\title{
On the Vertical Displacement of Small Stones in a Shallow Pond by Freezing*
}

\author{
Tetsuo Ohata**
}

\begin{abstract}
Vertical displacements of small stones were observed in a shallow pond located at the circumference of a glacial lake in Hongu Khola, Eastern Nepal. In the evening, stones were at the bottom of the shallow pond, but the next morning they were trapped at the surface of the frozen pond. Stones were displaced vertically during the night. An experiment to investigate the mechanism of this phenomenon was carried out. Some possible processes were found. It was also shown that repetition of this phenomenon will lead to the horizontal movement of stones.
\end{abstract}

\section{Introduction}

There are causes that will induce vertical displacements of soil, stones and other ground masses is periglacial regions. The most important one in frost action, but there are other causes such as freezing of water in a lake or a pond. The phenomenon which will be reported in this paper is the result of the latter process.

During the stay in the periglacial region, it was observed that small stones which were at the bottom of a shallow pond in the evening were trapped at the surface of the frozen pond the next morning.

An experiment was carried out to study the mechanism of this phenomenon during Oct. 16-19, 1976.

\section{Procedure of experiment}

The site of the experiment was the pond at the circumference of a glacial lake at the terminus of Hongu Nup Glacier (Glacier HX 220), Hongu Valley, Eastern Nepal. The position of the pond is $27^{\circ} 49^{\prime} 55^{\prime \prime} \mathrm{N}, 86^{\circ} 55^{\prime} 25^{\prime \prime} \mathrm{E}$. Fig. 1 shows the site of the experiment. The pond was connected to the glacial lake and the water level of the lake flucutated day by day. The sediment of the pond was mainly composed of silt with some sands. Patterned ground consisting of polygons of few tens of $\mathrm{cm}$ and stone stripes was found around the pond.

At the beginning of the experiment, stones with

* Glaciological Expedition of Nepal, Contribution No. 56

** Water Research Institute, Nagoya University, Nagoya 464

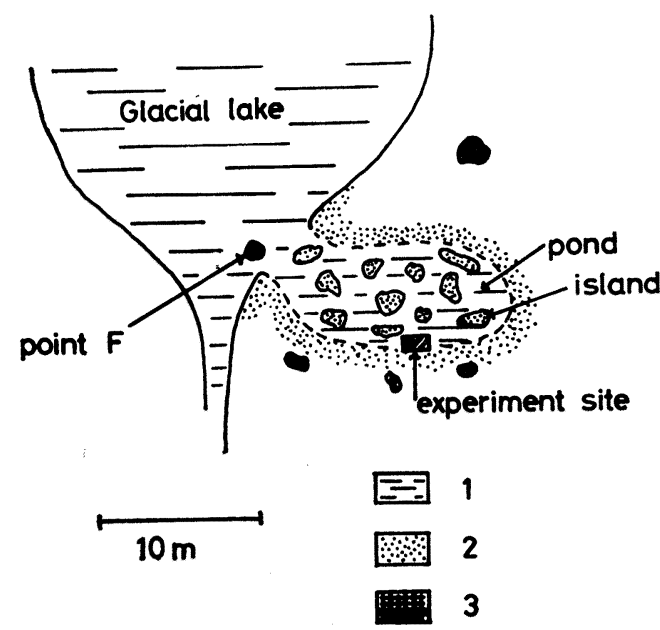

Fig. 1. The glacial lake, the pond and the site of the experiment. Point $\mathrm{F}$ is the point where the water level of the glacial lake was measured. 1- water body, 2- silt with some sand and stones, 3-large rock

diameters of 1 to $30 \mathrm{~mm}$ were placed in one line at the bottom of the pond. The depth of the pond was $10-15 \mathrm{~mm}$ different in different places.

The vertical as well as horizontal positions of the stones and the depth of the pond were measured by a tape when this was possible. Otherwise they were estimated by eye measurement.

The direction of freezing of water was checked by elongated bubbles in the ice.

\section{Observation results}

The phenomenon observed is shown schematically in Fig. 2. A and B show the situations in the 
A

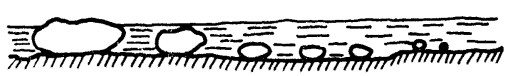

B

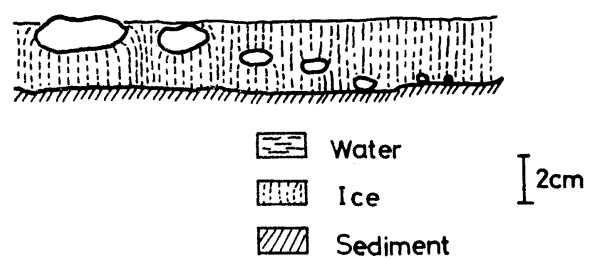

Fig. 2. A schematic model of the vertical displacement of stones during the night.

$A$ is the position in the evening before the freezing began. $\mathrm{B}$ is the position in the next morning.

The direction of the dashed line showing ice indicates the direction of the elongated bubbles.

evening and the next morning respectively. In the evening (A), the depth of the water was about 10 $\mathrm{mm}$. The top part of the large stones $(15-30 \mathrm{~mm})$ were above or near the surface of the pond, and the small ones $(1-10 \mathrm{~mm})$ were well underneath the surface of the pond. The same place after the freezing of the water in the night became as in B in Fig. 2. The depth of the pond had increased, and the position of the stones had changed. Large stones maintained the depth from the surface, but not the small ones. Small stones were at the bottom. Stones of intermediate sizes were inbetween them.

The ice started to melt before noon and in early afternoon it became as it was in the evening the day before. This phenomenon occurred in all 3 nights when the experiment was carried out.

Table 1. Amount of increase in the depth of water near the stone at the experimental site for 3 nights.

\begin{tabular}{c|c}
\hline PERIOD & $\begin{array}{c}\text { INCREASE AMOUNT } \\
\text { OF WATER DURING } \\
\text { THE NIGHT }\end{array}$ \\
\hline OCT. $16,16: 10-17,9: 10$ & $15 \mathrm{~mm}$ \\
$17,15: 45-18,7: 00$ & 12 \\
$18,16: 30-19,7: 20$ & 30 \\
\hline AVERAGE & 19 \\
\hline
\end{tabular}

The increase in the water depth is shown in Table 1 for 3 nights. The values varied amoung the 3 nights, the average value being $19 \mathrm{~mm}$.
The bubbles formed in the ice after nocturnal freezing were elongated in the vertical direction where there were no stones nearby. On the other hand, near the stones, they were orientated toward the stones. As these bubbles show the direction of the ice growth, it can be considered that water started to freeze from the surface, gradually downwards at places with no stones nearby. Near the stones it started from the periphery of the stones.

Stratified structures which show a change in the freezing speed or a time gap in freezing were not the ice.

The water level at point $\mathrm{F}$ in Fig. 1 is shown in Fig. 3. This shows the water level change at the found in glacial lake.

\section{Discussion}

\subsection{Vertical displacement of stones}

One possible mechanism for this phenomenon can be considered as below.

After sunset the surface of the pond starts to freeze owing to radiative cooling. Water starts to freeze from the periphery of the stones. This can be confirmed by the direction of the bubbles around the stones already noted in sec. 3. So the stones of which the top part is above or near the surface of the pond are trapped in the layer of ice early in the night, and preserving the position relative to the surface of the pond. After the water freezes down to an intermediate depth, water will flow into this site by a process described afterwards. When this occurs, the ice layer which is trapping the stone will float above the water. If we take an area of $10 \mathrm{~cm}^{2}$ around the stone, the thickness of ice needed to float a stone of $20 \mathrm{~mm}$ in diameter will be $4-5 \mathrm{~mm}$. This value seems to be reasonable to explain the possibility of floating, since the depth of the pond was about $10 \mathrm{~mm}$ before the inflow of the water.

Small stones which were well below the water surface at the beginning of the night will still stay at the bottom of the pond at the time of the inflow of the water. They will be trapped in the ice at later hours of the night. So in the morning, the situation will be as in B in Fig. 2 .

The inflow of water will be from the glacial lake which is connected to the pond. The water level of the glacial lake is shown in Fig. 3, but data during the nighttime are not available. Only the data of the evenings of Oct. 17 and 18 and of the mornings of Oct. 18 nad 19 were taken. From these data alone no conclusion can be reached on 


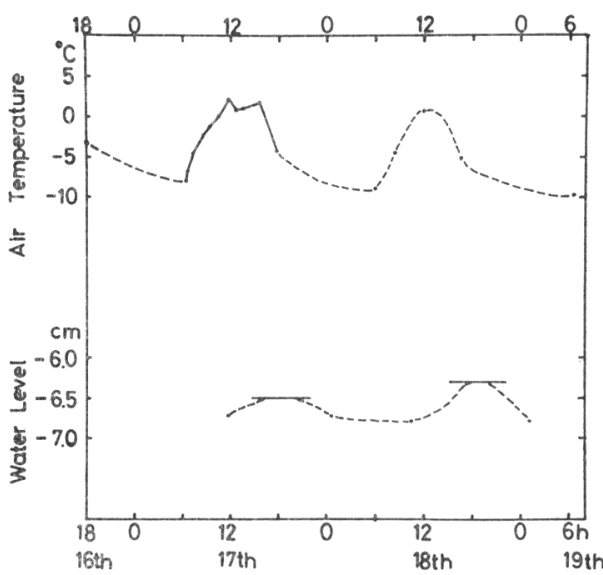

Fig. 3. Air temperature at the site, and water level at the glacial lake observed at point $F$ during Oct. 16-19, 1976. The solid line in the figure shows the actual trend. The horizontal line in the graph of water level shows the position of the ice piece.

the water level in the nighttime. However, in each morning a piece of ice was sticking to the rock (point F) at a position a little above the water surface. From this piece of ice, the level of the water surface in the night at the glacial lake can be estimated. This level is shown in Fig. 3 by the horizontal lines. The maximum level during the night may be higher than this level. For the nights of Oct. 17 and 18, the amount of the rise in water level were 2 and $5 \mathrm{~mm}$ respectively. This situation means that water will be supplied to the pond which was connected to the glacial lake with a channel. This amount alone is not enough to explain the depth change of the pond. There is a possibility that maximum level of the pond during the night was higher than the above-noted amount, and also some factors such as wind may have blown and supplied enough water to the pond.

Another one is the possibility of water movement within the pond. As the pond was connected to the glacial lake with a shallow channel, this channel may have froze early in the night and disconnected the pond from the glacial lake. If this happened, a part of the pond will form a closed system. The surface of the pond and the outer edge of this part will be frozen. Due to the volume change at the time of freezing, the pressure of water body inside the sheet of ice will be intensified. Water will move to places where the ice sheet could rise. This would be where the pond is relatively deep and much water still exists. The experimental site was relatively deep in that area and movement of water to this place may have occurred. In this case, the thin ice layer at the surface will not be floating. If this occurred, there should have been quite a difference in the level of the ice surface at the experimental site in the morning. This was not checked, and is left as a possible process.

Two possible mechanism have been explained, but neither one can completely explain the phenomenon with the data obtained so far. At this moment, the first one, the inflow of water due to the rise in water level at the glacial lake is thought as the most probable mechanism.

4.2 Horizontal movement due to the phenomenon

The horizontal movement of stones due to the vertical displacement of stones will be shown. In Fig. 4, photographs of the experimental site are shown. A is the situation at the beginning, and $\mathrm{B}$ at the end of the observation, which had passed

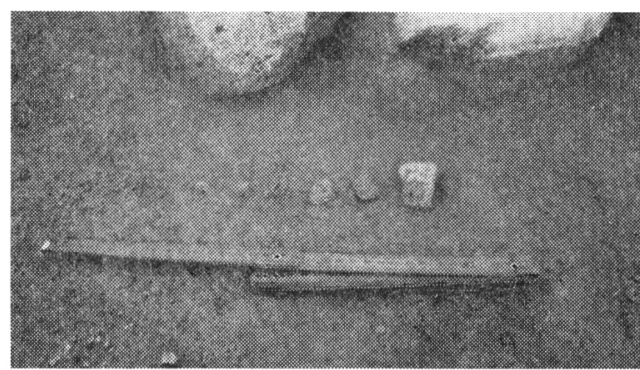

A

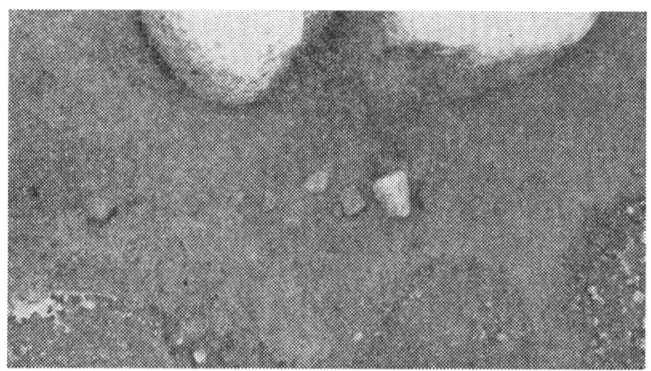

B

Fig. 4. The situation at the experimental site at the beginning (A) and at the end (B) of the experiment.

A-16:30, Oct. 16 B-16:45, Oct. 18.

the time period of 48 hours, that is two nights. Stones were placed in one line at the beginning, but were disordered at the end. One stone of medium size moved more than $2 \mathrm{~cm}$. The direction of the movement was to the lower part of the pond. This movement probably occurred when stone dropped to the bottom of the pond as the 
ice melted in the daytime. As the bottom of the the procedure of freezing, and the movement of pond was inclined, stones which dropped irregularly water in the pond and at the channel between the moved to lower places. glacial lake and the pond should be observed.

\section{Concluding remark}

Repetition of the vertical displacement leads to

The vertical displacement of small stones during the freezing of the pond in the nighttime is reported.

A few possible mechanism are considered. In order to investigate this phenomenon further, phology. the horizontal movement of stones which can be considered as one type of cryoturbation. If this occurred in a wide area and a long period, this would be an important process in periglacial mor- 